\title{
Correlation between switching to n-type conductivity and structural defects in highly Mg-doped InN
}

\begin{abstract}
Sergey Khromov, Per O A Persson, X. Wang, A. Yoshikawa, Bo Monemar, Johanna Rosén,
\end{abstract} Erik Janzén and Vanya Darakchieva

\section{Linköping University Post Print}

\section{Tweet}

N.B.: When citing this work, cite the original article.

Original Publication:

Sergey Khromov, Per O A Persson, X. Wang, A. Yoshikawa, Bo Monemar, Johanna Rosén, Erik Janzén and Vanya Darakchieva, Correlation between switching to n-type conductivity and structural defects in highly Mg-doped InN, 2015, Applied Physics Letters, (106), 23.

http://dx.doi.org/10.1063/1.4922301

Copyright: American Institute of Physics (AIP) http://www.aip.org/

Postprint available at: Linköping University Electronic Press http://urn.kb.se/resolve?urn=urn:nbn:se:liu:diva-120046 


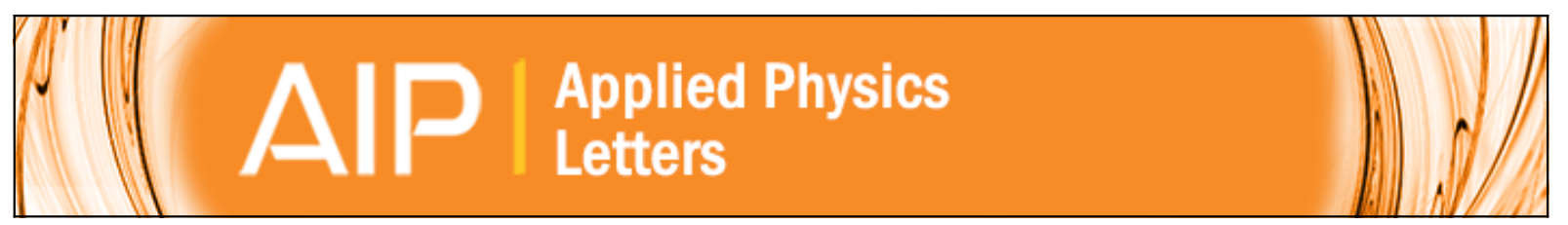

Correlation between switching to $n$-type conductivity and structural defects in highly Mg-doped InN

S. Khromov, P. O. Å. Persson, X. Wang, A. Yoshikawa, B. Monemar, J. Rosen, E. Janzén, and V. Darakchieva

Citation: Applied Physics Letters 106, 232102 (2015); doi: 10.1063/1.4922301

View online: http://dx.doi.org/10.1063/1.4922301

View Table of Contents: http://scitation.aip.org/content/aip/journal/apl/106/23?ver=pdfcov

Published by the AIP Publishing

\section{Articles you may be interested in}

Impact of Mg concentration on energy-band-depth profile of Mg-doped InN epilayers analyzed by hard X-ray photoelectron spectroscopy

Appl. Phys. Lett. 103, 162110 (2013); 10.1063/1.4826094

$\mathrm{N}$-type conductivity and properties of carbon-doped $\ln \mathrm{N}(0001)$ films grown by molecular beam epitaxy

J. Appl. Phys. 113, 033501 (2013); 10.1063/1.4775736

Defect evolution and interplay in n-type $\ln \mathrm{N}$

Appl. Phys. Lett. 100, 091907 (2012); 10.1063/1.3688038

Vacancy-type defects in Mg-doped InN probed by means of positron annihilation

J. Appl. Phys. 105, 054507 (2009); 10.1063/1.3075907

Polarity inversion in high Mg-doped In-polar InN epitaxial layers

Appl. Phys. Lett. 91, 081912 (2007); 10.1063/1.2773762

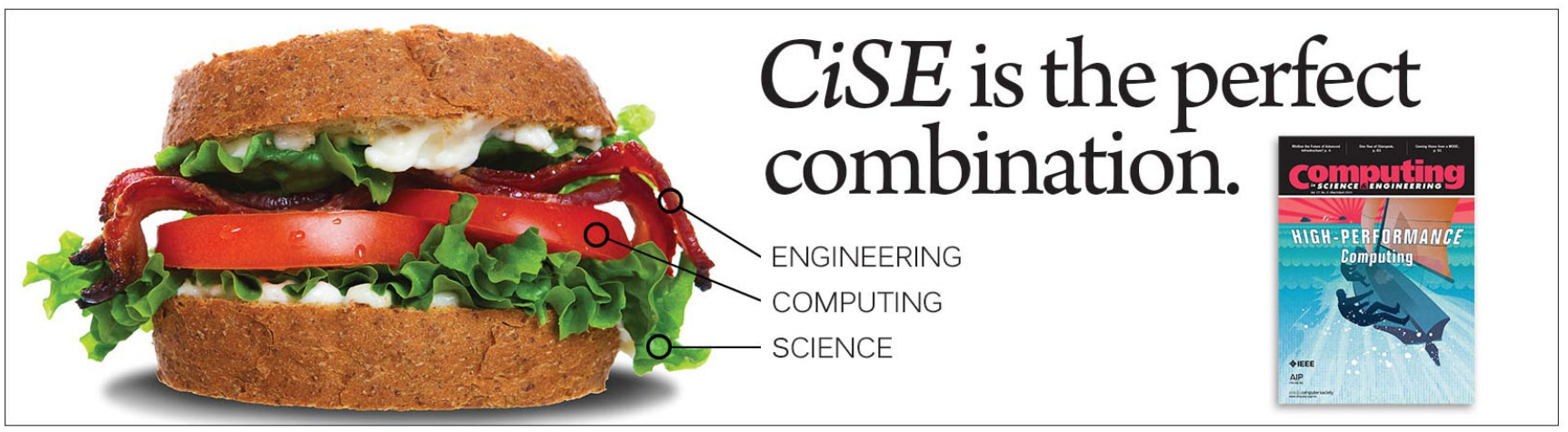




\title{
Correlation between switching to n-type conductivity and structural defects in highly Mg-doped InN
}

\author{
S. Khromov, ${ }^{1}$ P. O. A. Persson, ${ }^{1}$ X. Wang, ${ }^{2}$ A. Yoshikawa, ${ }^{3}$ B. Monemar, ${ }^{1}$ J. Rosen, ${ }^{1}$ \\ E. Janzén, ${ }^{1}$ and V. Darakchieva ${ }^{1, a)}$ \\ ${ }^{1}$ Department of Physics, Chemistry, and Biology (IFM), Linköping University, S-581 83 Linköping, Sweden \\ ${ }^{2}$ State Key Laboratory of Artificial Microstructure and Mesoscopic Physics, Peking University, \\ Beijing 100871, China \\ ${ }^{3}$ Center for SMART Green Innovation Research, Chiba University, Chiba 263-8522, Japan
}

(Received 15 March 2015; accepted 27 May 2015; published online 8 June 2015)

\begin{abstract}
The effect of $\mathrm{Mg}$ doping on the microstructure of $\mathrm{InN}$ epitaxial films in relation to their free-charge carrier properties has been investigated by transmission electron microscopy (TEM) and aberration corrected scanning TEM. We observe a direct correlation between $\mathrm{Mg}$ concentration and the formation of stacking faults. The threading dislocation density is found to be independent of $\mathrm{Mg}$ concentration. The critical Mg concentration for the on-set of stacking faults formation is determined and found to correlate with the switch from $p$ - to $n$-type conductivity in InN. Potential mechanisms involving stacking faults and point defect complexes are invoked in order to explain the observed conductivity reversal. Finally, the stacking faults are structurally determined and their role in the reduction of the free electron mobility in highly doped $\mathrm{InN}: \mathrm{Mg}$ is discussed. (C) 2015 AIP Publishing LLC. [http://dx.doi.org/10.1063/1.4922301]
\end{abstract}

Accurate control of p-type doping in InN is a critical issue on the way to material implementation in advanced electronic devices such as next generation solar cells, light emitting diodes, ${ }^{1,2}$ and terahertz emitters. ${ }^{3}$ So far, only $\mathrm{Mg}$ has been shown as a working acceptor for $\mathrm{InN} .{ }^{4}$ Due to peculiarities of energy band structure, intrinsic $\mathrm{InN}$ is extremely prone to $n$-type behavior. Therefore, obtaining $p$-type $\mathrm{InN}$ proves a challenge and large concentrations $\left(10^{18}-10^{20} \mathrm{~cm}^{-3}\right)$ of $\mathrm{Mg}$ need to be incorporated to overcome the inherent $n$-type conductivity. Furthermore, reliable measurements of free hole properties with standard contact-based electrical methods are difficult due to the inversion electron layer formed at the InN surface, as a result of Fermi energy pinning. ${ }^{5}$ To detect $p$-type conductivity and assess the freecharge carrier (FCC) properties, non-trivial methods are used such as electrolyte capacitance-voltage (ECV) measurements, ${ }^{4}$ thermopower measurements, ${ }^{6}$ or, as it was shown recently, infrared spectroscopic ellipsometry (IRSE). ${ }^{7,8}$

It has lately been demonstrated that doping of $\mathrm{InN}$ with $\mathrm{Mg}$ results in a $p$-type conductivity window in the range of $1.0 \times 10^{18} \mathrm{~cm}^{-3} \leq[\mathrm{Mg}] \leq 2.9 \times 10^{19} \mathrm{~cm}^{-3}$. $7-9$ Holes from ionized $\mathrm{Mg}$ acceptors in concentrations less than $1.0 \times 10^{18} \mathrm{~cm}^{-3}$ are not sufficient to compensate for the electrons from intrinsic donor defects and such $\mathrm{InN}$ material is $n$ type. Once $\mathrm{Mg}$ concentration reaches $1.0 \times 10^{18} \mathrm{~cm}^{-3}$, InN becomes $p$-type. Switching of conductivity again from $p$ - to $n$-type at $[\mathrm{Mg}] \geq 1.8 \times 10^{20} \mathrm{~cm}^{-3}$ was tentatively ascribed to $\mathrm{Mg}$ induced donor defects. Indications of zinc-blende formation $^{7,10}$ and polarity inversion ${ }^{11,12}$ accompanied the switch to $n$-type conductivity at high $\mathrm{Mg}$ doping. Despite existing reports, ${ }^{10,12-14}$ the relationship between $\mathrm{Mg}$ doping, defect formation, and FCC properties in wurtzite $\mathrm{InN}$ is not fully understood and requires further investigation.

\footnotetext{
${ }^{a}$ E-mail: vanya.darakchieva@liu.se
}

In this paper, we present a comprehensive (scanning) transmission electron microscopy [(S)TEM] investigation of $\mathrm{InN}$ layers doped with $\mathrm{Mg}$ through a wide concentration range in relation to their FCC properties. A total of six samples were investigated, one of which was undoped, intrinsically $n$-type, while the remaining had the following $\mathrm{Mg}$ concentrations: $1.0 \times 10^{18} \mathrm{~cm}^{-3}, \quad 5.6 \times 10^{18} \mathrm{~cm}^{-3}$, $2.9 \times 10^{19} \mathrm{~cm}^{-3}, \quad 1.8 \times 10^{20} \mathrm{~cm}^{-3}$, and $8.0 \times 10^{20} \mathrm{~cm}^{-3}$ (Table I). The three lower doped samples were $p$-type, whereas the two higher doped ones- $n$-type, as was previously confirmed by IRSE, ${ }^{7}$ ECV, and FTIR. ${ }^{15}$ The InN samples were wurtzite, c-plane oriented and grown with intended In-polarity on $4.1-\mu$ m-thick $\mathrm{GaN} / \mathrm{c}-\mathrm{Al}_{2} \mathrm{O}_{3}$ templates by plasma-assisted molecular beam epitaxy at $480^{\circ} \mathrm{C}$. The growth of 400-nm-thick $\mathrm{Mg}$-doped $\mathrm{InN}$ was always preceded by 50 -nm-thick undoped $\mathrm{InN}$ layer. Detailed information about the growth procedure has been reported elsewhere. ${ }^{15}$

Cross-sectional samples for the (S)TEM investigations were prepared by conventional methods, starting with mechanical cutting, gluing, and polishing, followed by low energy Ar-ion milling to electron transparency. TEM studies were performed using FEI Tecnai G2 TF20 UT $200 \mathrm{keV}$ FEG microscope. The TEM images were taken in conventional bright-field TEM mode with electron beam parallel to $\langle 11-20\rangle$, which allows the visualization of $\mathrm{a}, \mathrm{c}$, and $\mathrm{a}+\mathrm{c}$ dislocations with a predominant c-type nature. ${ }^{16}$

High-angle annular dark field (HAADF) STEM imaging was performed using the Linköping double corrected FEI $\operatorname{Titan}^{3} 60-300$ at $300 \mathrm{kV}$. STEM probe had a $21 \mathrm{mrad}$ semiangle convergence at a camera length of $145 \mathrm{~cm}$. Typical image size was $2048 \times 2048$ pixel with dwell time of $20 \mu \mathrm{s}$ (total frame time of $100 \mathrm{~s}$ ). The typical beam current was about 50-100 pA.

Figures 1(a)-1(f) show overview TEM images of the $\sim 400$-nm-thick InN epitaxial layers with increasing $\mathrm{Mg}$ doping from (a) to (f), where (a) represents the undoped 
TABLE I. Properties of the studied set of InN samples: Mg concentration, $[\mathrm{Mg}]$, bulk free-charge carrier concentration, $N$, mobility, $\mu$, threading dislocation (TD) density, and stacking fault (SF) density.

\begin{tabular}{lccccc}
\hline \hline Sample & {$[\mathrm{Mg}]\left(\mathrm{cm}^{-3}\right)$} & $N^{7}\left(\times 10^{17} \mathrm{~cm}^{-3}\right)$ & $\mu^{7}\left(\mathrm{~cm}^{2} / \mathrm{V} \cdot \mathrm{s}\right)$ & TD density $\left(\mathrm{cm}^{-2}\right)$ & $\mathrm{SF}_{\text {density }\left(\mathrm{cm}^{-1}\right)}$ \\
\hline E925 & Undoped & $11.6 \pm 0.5(\mathrm{n})$ & $1601 \pm 87$ & $7 \times 10^{9}$ & $6 \times 10^{9}$ \\
E942 & $1.0 \times 10^{18}$ & $3.3 \pm 0.1(\mathrm{p})$ & $21 \pm 1$ & $7 \times 10^{9}$ & 0 \\
E941 & $5.6 \times 10^{18}$ & $1.6 \pm 0.1(\mathrm{p})$ & $24 \pm 1$ & $5 \times 10^{9}$ & 0 \\
E940 & $2.9 \times 10^{19}$ & $3.3 \pm 0.1(\mathrm{p})$ & $30 \pm 2$ & $6 \times 10^{9}$ & 0 \\
E924 & $1.8 \times 10^{20}$ & $9.20 \pm 0.04(\mathrm{n})$ & $1079 \pm 40$ & $4 \times 10^{9}$ & $6 \times 10^{10}$ \\
E930 & $8.0 \times 10^{20}$ & $77 \pm 0.3(\mathrm{n})$ & $203 \pm 4$ & & $6 \times 10^{10}$ \\
\hline \hline
\end{tabular}

intrinsically n-type sample. Threading dislocation (TD) densities were assessed from these images and are summarized with other sample properties in Table I. As can be seen from the figures, the apparent TDs nucleate at the InN/GaN interface, supposedly due to lattice mismatch and propagate all the way through the $\mathrm{Mg}$ doped $\mathrm{InN}$ layer. The estimated TD densities are in the range of $4-8 \times 10^{9} \mathrm{~cm}^{-2}$ and vary negligibly through the doping range. The density of TDs in the same set of samples was previously measured by XRD. ${ }^{7}$ The numbers of edge type dislocations, which are the predominant type of dislocations in InN, were slightly higher, in the $1-2 \times 10^{10} \mathrm{~cm}^{-2}$ range, but also proved to be independent with $\mathrm{Mg}$ doping. ${ }^{7}$ In the sample with the highest $\mathrm{Mg}$ content (Fig. 1(f)), TDs may be partly obstructed by the high density of stacking faults (SFs) present in the layer. This can explain a small decrease in the number of TDs estimated from this specimen.

Apart from TDs that are present in all studied samples, SFs were found in the two samples with the highest Mg content; no SFs were observed in the $p$-type or intrinsic $n$-type InN samples. To estimate the SF density and determine their structure on the atomic level, aberration corrected STEM was employed. In Fig. 2(a), an overview STEM image of the sample with $[\mathrm{Mg}]=1.8 \times 10^{20} \mathrm{~cm}^{-3}$ is shown. The visualization of specimen microstructure is promoted by enhanced diffraction contrast conditions in STEM mode. A clearly visible $\mathrm{V}$-shaped contrast appears at the interface between the 50-nm-thick undoped InN buffer layer and the $\sim 400$-nm-thick
Mg doped InN. In the top part of the Mg doped layer, SFs are identified as white horizontal lines. Further magnifications are shown in Fig. 2(b) and atomic resolution is shown in Fig. 2(c). In this figure, primarily, the heavier In atoms are resolved due to the $\sim Z^{2}$ promoted mass-contrast. A single column is highlighted for reference and present SFs are identified by yellow horizontal lines. As can be seen, the stacking sequence changes several times from the wurtzite $\mathrm{AaBb}$ sequence (capital letters denote In atoms, while small letters- $\mathrm{N}$ atoms) to $\mathrm{AaBbCc}-I_{1}$ type $\mathrm{SF}$, which can be viewed as a local sheet of zinc-blende InN. This stacking fault requires the least amount of energy compared to other SF types and is consequently the most commonly observed. Additional SF geometries include a type $2-I_{2}$ fault; however, only a single $I_{2}$ type fault is observed in this image. An $I_{2}$ type fault constitutes a change of stacking from $\mathrm{AaBb}$ to $\mathrm{AaBbCcAa}$ and requires about twice the formation energy as for $I_{1} \mathrm{SF}$ energy and is therefore less likely to form. ${ }^{17}$ The slight misalignment of the atom sequence of $I_{2}$ in Fig. 2(c) may be related to image drift due to charging during the acquisition. However, additional factors play a role too. For instance, using a high camera length to increase the signal-tonoise ratio leads to additional diffraction contrast resulting in slightly different appearances of different symmetry positions.

Fig. 3(a) is an overview high resolution STEM (HRSTEM) image of the highest doped sample $([\mathrm{Mg}]=8$ $\times 10^{20} \mathrm{~cm}^{-3}$ ). The highlighted rectangle in Fig. 3(a) is magnified to atomic resolution in Fig. 3(b). This micrograph
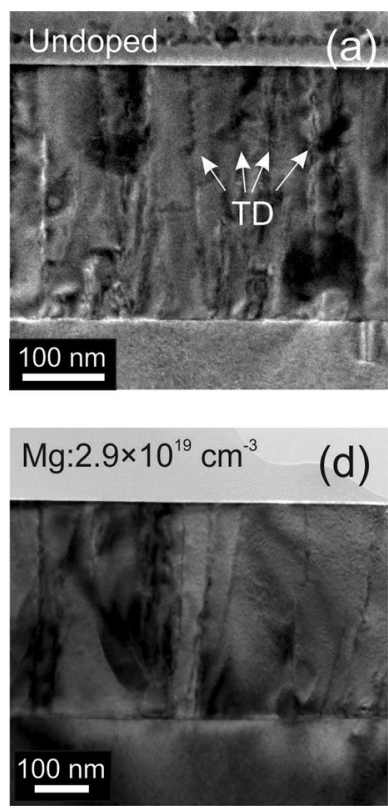
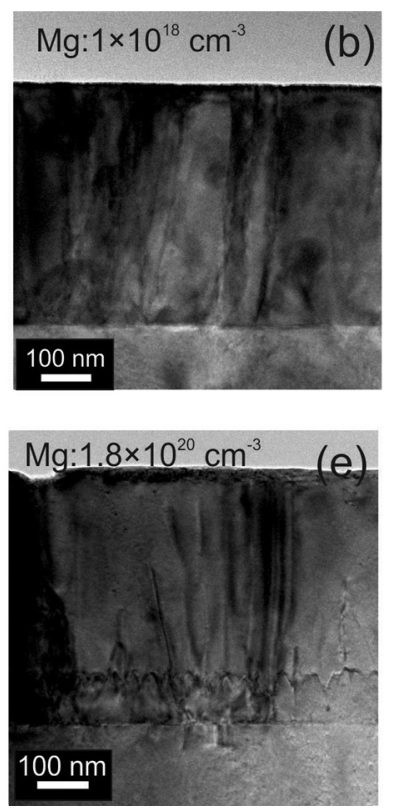
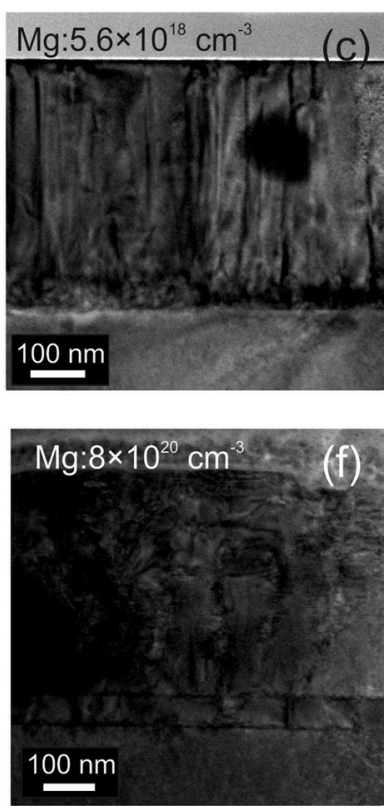

FIG. 1. Cross-sectional TEM images showing TDs in the undoped $\mathrm{InN}-$ (a), and the InN films doped by $\mathrm{Mg}$ with concentrations: $1.0 \times 10^{18} \mathrm{~cm}^{-3}$ (b), 5.6 $\times 10^{18} \mathrm{~cm}^{-3}$ (c), $2.9 \times 10^{19} \mathrm{~cm}^{-3}$ (d), $1.8 \times 10^{20} \mathrm{~cm}^{-3}(\mathrm{e})$, and $8.0 \times 10^{20} \mathrm{~cm}^{-3}$ (f). The dark spot in Fig. 1(c) appears due to the redeposition of the material during ion-milling. 

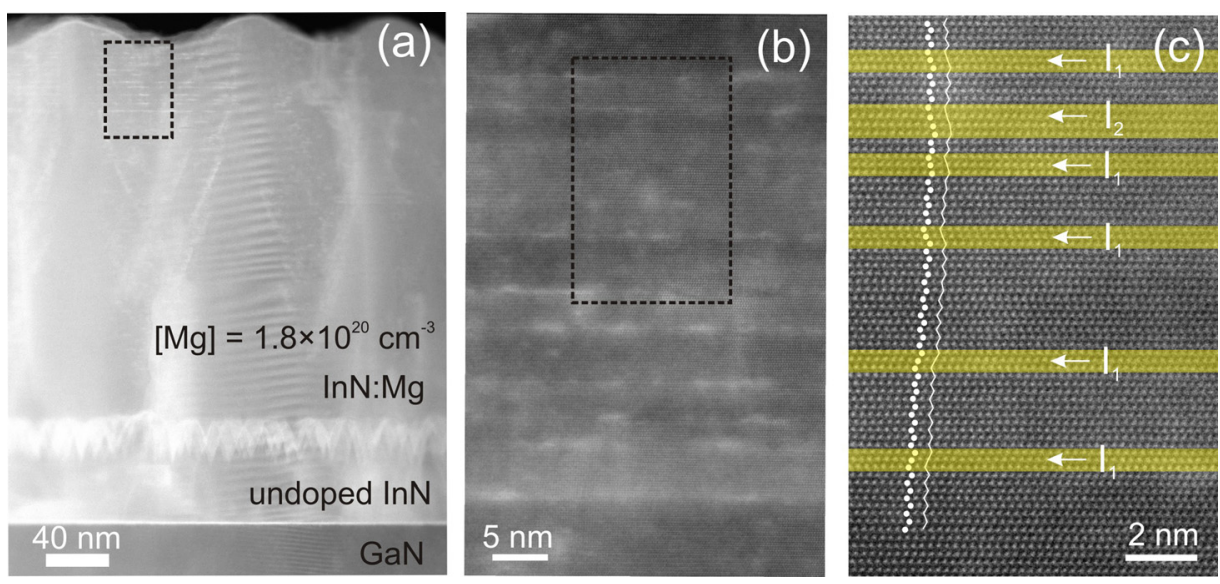

reveals a higher density of SFs of both types compared to the previous sample. Locally, $I_{1}$-type $S F s$ also form bundles. From Fig. 4, acquired from the highest doped sample, it is apparent that the formation of SFs is initiated immediately after the onset of $\mathrm{Mg}$ doping. The observed numerous SFs, constituting local zinc-blende sheets, can explain peaks which were previously observed by reciprocal space mapping and attributed to zinc-blende $\mathrm{InN}$ inclusions in these samples. $^{7}$

From the present observations, it is apparent that $\mathrm{Mg}$ doping of $\mathrm{InN}$ at concentrations above $1.8 \times 10^{20} \mathrm{~cm}^{-3}$ leads to material quality deterioration and the nucleation of SFs. However, there can be several mechanisms responsible for $\mathrm{SF}$ formation-directly or indirectly linked to $\mathrm{Mg}$ atom incorporation in the InN lattice. As one can see from the TEM images in Figs. 1(e) and 1(f) and, at larger magnification, in Figs. 5(a) and 5(b), the $\mathrm{Mg}$ doped $\mathrm{InN}$ layer is delineated from the undoped $\mathrm{InN}$ buffer with $\mathrm{V}$-shaped contrast. Such V-shaped defects were previously confirmed to be a sign of polarity inversion in InN. ${ }^{11,12}$ InN surface with In- and N-oriented polarities has different bonding configuration and adsorption/desorption properties. ${ }^{14}$ Consequently, different III/V ratios and growth temperatures are used to grow In- and N-polar InN. Change of polarity induced by $\mathrm{Mg}$ doping means that $\mathrm{N}$-polar material starts to grow in
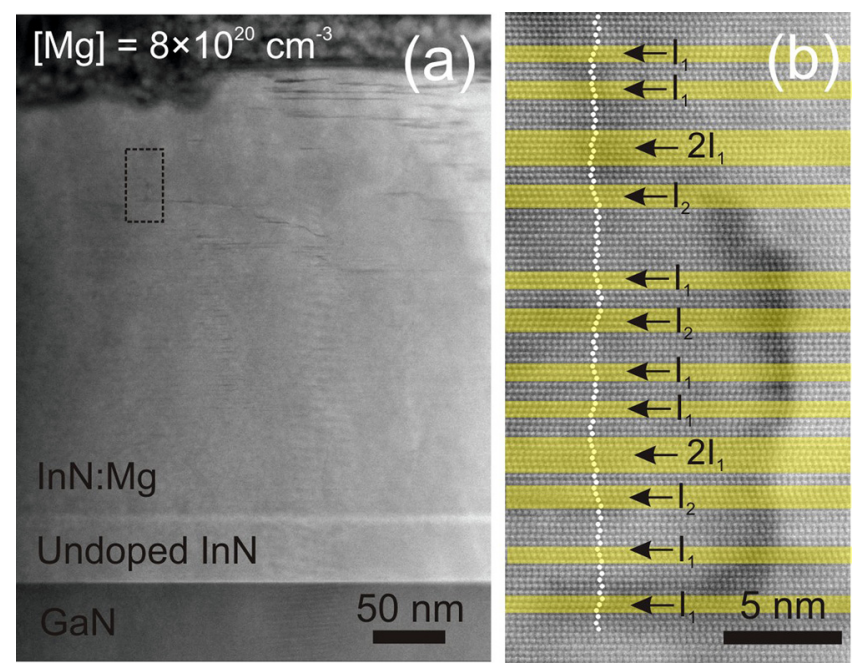

FIG. 3. HRSTEM images showing SFs in the InN film with Mg concentration of $8.0 \times 10^{20} \mathrm{~cm}^{-3}$. conditions unoptimized for N-polar InN. Therefore, it is reasonable to assume that two major sources of nucleation for SFs can be point defects formed due to non-optimal growth conditions as well as an increasing number of $\mathrm{Mg}$ atoms in the InN lattice.

The present results show that the on-set of SF generation coincides with the switching from $p$ - to $n$-type conductivity in InN. The SF can be regarded as a very thin zinc-blende layer embedded in the wurtzite matrix, i.e., as a polytypic quantum well. The band offsets at the interface between the wurtzite and zinc-blende InN have been calculated to be type I with $104-130 \mathrm{meV}$ and $57-93 \mathrm{meV}$ for the conduction and the valence bands, respectively. ${ }^{18}$ The large valence band offset implies that holes can be confined in the zinc-blende quantum well-like region, which can lead to reduction of free hole concentration. Furthermore, the discontinuity of the spontaneous polarization across the interface shows that the band bending will produce a triangular potential in the barrier which may also confine holes. Similar localization should also occur for electrons. Rigorous first principle calculations have shown that in contrast to electrons, holes are localized not only in the zinc-blende but also in the wurtzite InN. ${ }^{18}$ This suggests that the localization of holes due to SFs may play a role for the conductivity reversal. However, other factors, such as point defects and impurity complexes, are

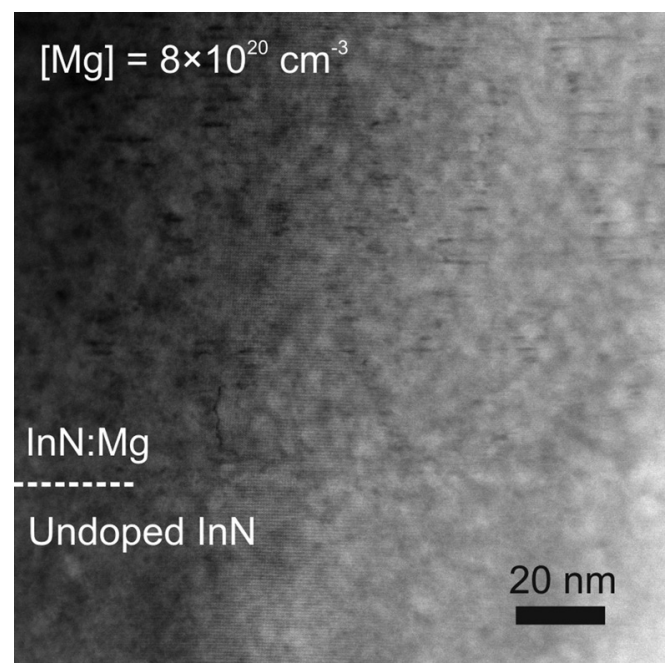

FIG. 4. HRSTEM image showing the interface structure of the $\mathrm{InN}$ film with $\mathrm{Mg}$ concentration of $8.0 \times 10^{20} \mathrm{~cm}^{-3}$. 

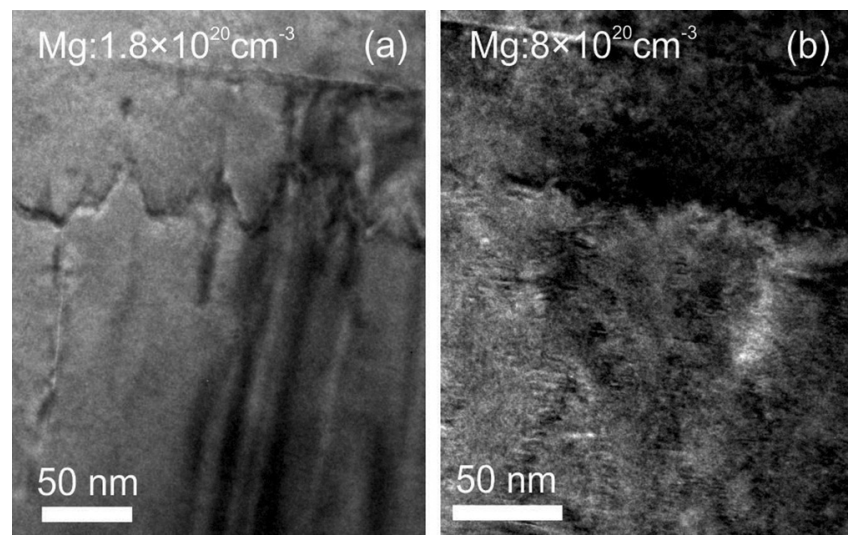

FIG. 5. TEM images showing V-shaped contrast which indicates switching from In- to N-polarity.

likely to have impact on the conductivity type in InN doped with high concentrations of Mg.

According to theoretical calculations, substitutional $\mathrm{Mg}_{\text {In }}$ acceptor atom tends to form complexes with an $\mathrm{O}_{\mathrm{N}}$ donor atom. ${ }^{19}$ Typically, InN films contain oxygen in the $10^{17}-10^{19} \mathrm{~cm}^{-3}$ concentration range. ${ }^{20}$ Oxygen incorporation can be further enhanced by switching to N-polarity during growth. In general, the crystallographic orientation strongly affects the impurity and dopant incorporation in IIInitrides. ${ }^{21}$ For instance, it is well known that N-polar GaN and $\mathrm{InN}$ tend to incorporate higher impurity concentrations compared to Ga- and In-polar material, respectively. ${ }^{21,22}$ $\mathrm{MgO}, \mathrm{Mg}_{2} \mathrm{O}_{2}$, and $\mathrm{Mg}_{2} \mathrm{O}_{3}$ are the complexes with the lowest formation energies in InN grown under In-rich conditions (our case). ${ }^{19} \mathrm{MgO}$ and $\mathrm{Mg}_{2} \mathrm{O}_{2}$ are neutral complexes, while $\mathrm{Mg}_{2} \mathrm{O}_{3}$ is a donor with -1 charge state. All these three defects can contribute to the acceptor compensation and the observed switching to $n$-type conductivity at $[\mathrm{Mg}] \geq 1.8 \times 10^{20} \mathrm{~cm}^{-3}$. Other point defects that can account for $n$-type conductivity at high $\mathrm{Mg}$ concentrations are single nitrogen vacancies or complexes of such. They were theoretically predicted to have the lowest formation energies among all point defects in $n$-type material grown under In-rich conditions. ${ }^{23}$

Experimentally, vacancy-type defects in $\mathrm{Mg}$ doped $\mathrm{InN}$ were studied by Uedono et $a l^{24}$ by positron annihilation spectroscopy. In their case, the switch to $n$-type conductivity occurred at $[\mathrm{Mg}] \geq 3 \times 10^{19} \mathrm{~cm}^{-3}$, and it was attributed to In-vacancy and N-vacancy clusters- $\mathrm{V}_{\text {In }}\left(\mathrm{V}_{\mathrm{N}}\right)_{3}{ }^{20}$ Such complex, however, is expected to exhibit a very high formation energy as predicted by first-principles calculations ${ }^{23}$ and therefore more difficult to form.

Charge carrier mobility is known to be affected by the concentration of point defects in semiconductors. As can be seen from Table I, electron mobility in the $n$-type samples with the two highest $\mathrm{Mg}$ concentrations experience a substantial decrease compared to the undoped $n$-type $\mathrm{InN}$-from $1601 \pm 87 \mathrm{~cm}^{2} / \mathrm{V} \cdot \mathrm{s}$ in the undoped InN to $1079 \pm 40 \mathrm{~cm}^{2} / \mathrm{V} \cdot \mathrm{s}$ for the sample with $[\mathrm{Mg}]=1.8 \times 10^{20} \mathrm{~cm}^{-3}$ and 203 $\pm 4 \mathrm{~cm}^{2} / \mathrm{V} \cdot \mathrm{s}$ for the sample with $[\mathrm{Mg}]=8 \times 10^{20} \mathrm{~cm}^{-3}$. The TD densities in these two highest doped samples are very similar (Table I). SF density, on the other hand, increases with $\mathrm{Mg}$ content. As the number of SFs correlates with the deterioration of the InN FCC properties, we propose that SFs may affect the electron mobility themselves or serve as a signature for the increased concentration of point defects that affect charge carrier properties of the material.

In conclusion, we have presented a (S)TEM investigation of the structural properties in a set of $\mathrm{Mg}$ doped $\mathrm{InN}$ films in relation to their FCC properties. TD densities are found to be independent of $\mathrm{Mg}$ doping. On the other hand, SFs have been identified only in the samples with $[\mathrm{Mg}] \geq 1.8 \times 10^{20} \mathrm{~cm}^{-3}$ and the $p$-type InN films have been found to be free of SFs. Additionally, the onset of SF formation coincides with the switch in conductivity type from $p$ - to $n$-type. The SF density also correlates with the drop in FCC mobility in comparison with the undoped $n$-type $\mathrm{InN}$ (see Table I). We have discussed possible mechanisms involving SFs or point defects that may be responsible for the switching to $n$-type conductivity in InN at high Mg doping. SFs have also been suggested to play a role in the deterioration of electron mobility parameters or serve as a signature for increased concentration of point defects.

We acknowledge support from the Swedish Research Council (VR) under Grant Nos. 2008-405, 2012-4359, 2013-5580, 642-2013-8020, and ERC St. Grant No. 258509 the Swedish Governmental Agency for Innovation Systems (VINNOVA) under the VINNMER international qualification program, Grant No. 2011-03486, and the Swedish Foundation for Strategic Research (SSF), under Grant No. FFL12-0181. The Knut and Alice Wallenberg foundation is acknowledged for the support of the Electron microscopy laboratory in Linköping. X. Wang acknowledges the support from the National Basic Research Program of China (Grant No. 2012CB619300) and the National Natural Science Foundation of China (Grant Nos. 61225019 and 61376060).

${ }^{1}$ A. G. Bhuiyan, A. Hashimoto, and A. Yamamoto, J. Appl. Phys. 94, 2779 (2003).

${ }^{2}$ W. Walukiewicz, J. W. Ager III, K. M. Yu, Z. Liliental-Weber, J. Wu, S. X. Li, R. E. Jones, and J. D. Denlinger, J. Phys. D: Appl. Phys. 39, R83 (2006).

${ }^{3}$ G. D. Chern, E. D. Readinger, H. Shen, M. Wraback, C. S. Gallinat, G. Koblmüller, and J. S. Speck, Appl. Phys. Lett. 89, 141115 (2006).

${ }^{4}$ R. Jones, K. Yu, S. Li, W. Walukiewicz, J. Ager III, E. Haller, H. Lu, and W. Schaff, Phys. Rev. Lett. 96, 125505 (2006).

${ }^{5}$ I. Mahboob, T. Veal, C. McConville, H. Lu, and W. Schaff, Phys. Rev. Lett. 92, 036804 (2004).

${ }^{6}$ J. W. Ager III, N. Miller, R. E. Jones, K. M. Yu, J. Wu, W. J. Schaff, and W. Walukiewicz, Phys. Status Solidi B 245, 873 (2008).

${ }^{7}$ M.-Y. Xie, N. B. Sedrine, S. Schöche, T. Hofmann, M. Schubert, L. Hung, B. Monemar, X. Wang, A. Yoshikawa, K. Wang, T. Araki, Y. Nanishi, and V. Darakchieva, J. Appl. Phys. 115, 163504 (2014).

${ }^{8}$ S. Schöche, T. Hofmann, V. Darakchieva, N. B. Sedrine, X. Wang, A. Yoshikawa, and M. Schubert, J. Appl. Phys. 113, 013502 (2013).

${ }^{9}$ X. Wang, S.-B. Che, Y. Ishitani, and A. Yoshikawa, Appl. Phys. Lett. 92, 132108 (2008).

${ }^{10}$ Z. Liliental-Weber, M. E. Hawkridge, X. Wang, and A. Yoshikawa, Phys. Status Solidi C 7, 2025 (2010).

${ }^{11}$ J. Jasinski, Z. Liliental-Weber, H. Lu, and W. J. Schaff, Appl. Phys. Lett. 85, 233 (2004).

${ }^{12}$ X. Wang, S.-B. Che, Y. Ishitani, A. Yoshikawa, H. Sasaki, T. Shinagawa, and S. Yoshida, Appl. Phys. Lett. 91, 081912 (2007).

${ }^{13}$ Z. Liliental-Weber, in Indium Nitride Related Alloy, edited by T. Veal, C. McConville, and W. Schaff (CRS Press, Taylor \& Francis Group, Boca Raton, London, New York, 2008), pp. 515-540. 
${ }^{14}$ Y. Nanishi, T. Araki, and T. Yamaguchi, in Indium Nitride Related Alloy, edited by T. Veal, C. McConville, and W. Schaff (CRS Press, Taylor \& Francis Group, Boca Raton, London, New York, 2008), pp. 1-50.

${ }^{15}$ A. Yoshikawa, X. Wang, Y. Ishitani, and A. Uedono, Phys. Status Solidi A 207, 1011 (2010).

${ }^{16}$ V. Darakchieva, T. Hofmann, M. Schubert, B. E. Sernelius, B. Monemar, P. O. A ${ }^{\circ}$. Persson, F. Giuliani, E. Alves, H. Lu, and W. J. Schaff, Appl. Phys. Lett. 94, 022109 (2009).

${ }^{17}$ D. Hull and D. J. Bacon, Introduction to Dislocations, 5th ed. (Elsevier, 2011).

${ }^{18}$ A. Belabbes, L. C. de Carvalho, A. Schleife, and F. Bechstedt, Phys. Rev. B 84, 125108 (2011).
${ }^{19}$ X. Duan and C. Stampfl, Phys. Rev. B 79, 035207 (2009).

${ }^{20}$ C. S. Gallinat, G. Koblmüller, and J. S. Speck, Appl. Phys. Lett. 95, 022103 (2009).

${ }^{21}$ S. C. Cruz, S. Keller, T. E. Mates, U. K. Mishra, and S. P. DenBaars, J. Cryst. Growth 311, 3817 (2009).

${ }^{22}$ V. Darakchieva, K. Lorenz, M. Y. Xie, E. Alves, C. L. Hsiao, L. C. Chen, L. W. Tu, W. J. Schaff, T. Yamaguchi, and Y. Nanishi, J. Appl. Phys. 110, 063535 (2011).

${ }^{23}$ X. Duan and C. Stampfl, Phys. Rev. B 79, 174202 (2009).

${ }^{24}$ A. Uedono, H. Nakamori, K. Narita, J. Suzuki, X. Wang, S.-B. Che, Y. Ishitani, A. Yoshikawa, and S. Ishibashi, J. Appl. Phys. 105, 054507 (2009). 